\title{
Jornadas de Junho: uma leitura em quatro conceitos para a Ciência da Informação
}

\author{
The Journeys of June: a reading in four concepts for Information Science
}

\author{
Rubens da Silva Ferreira \\ Doutorando em Ciência da Informação pelo IBICT/UFRJ. \\ Docente da Faculdade de Biblioteconomia (FABIB/ICSA/UFPA) \\ E-mail: rubenspa@yahoo.com
}

\begin{abstract}
Resumo
O trabalho tem como objetivo contribuir para o entendimento das manifestações recentes no Brasil, as chamadas Jornadas de Junho. Nesta direção, faz-se um exercício teórico de discussão no campo da Ciência da Informação, empregando os conceitos de informação, rede, afetos e multidão, precisamente para dar conta de uma realidade que se revela desconcertante para os governos, para a grande mídia, para os agentes econômicos e para a própria sociedade. De um modo geral, o trabalho aponta para o peso das redes digitais na construção de estratégias infocomunicativas, orientadas para a ação política de indivíduos e de grupos, seja nas ruas e/ou na Internet. Em seu conjunto, essas singularidades que se encontram nas manifestações dão forma a uma multidão que encontra força nas redes digitais, onde potencializam ações na perspectiva da luta por melhores condições de vida no país, expressando o sentido político da informação.
\end{abstract}

Palavras-chave: Jornadas de Junho. Informação. Rede. Afetos. Multidão.

\begin{abstract}
The work has as objective to contribute for the understanding of the recent street manifestations in Brazil, the called Journeys of June. In this direction, it has done a theoretical exercise of discussion in the field of Information Science, using the concepts of information, networking, affects and multitude, accurately to be able to the big media of a reality that reveals disappointing to the governments, to the big media, to the economic agents and the own society. Generally, the work points to the importance of the digital networks in the construction of the infocommunicative strategies oriented to the political action of individuals and groups, both in the streets and/ or in the Internet. In the mass, these singularities that meet themselves in the street manifestations compose a multitude that finds power in the digital networks, where potentiate actions in the perspective of the campaign for better conditions of life in the country, expressing the political sense of the information.
\end{abstract}

Keywords: Journeys of June. Information. Network. Affects. Multitude.

InCID: R. Ci. Inf. e Doc., Ribeirão Preto, v. 6, n. 2, p. 5-19, set. 2015/fev. 2016.

DOI: 10.11606/issn.2178-2075.v6i2p5-19 


\section{Introdução}

Dia seis de junho, uma onda de manifestações teve início em São Paulo, seguiu para o Rio de Janeiro e irradiou-se pelo Brasil ao longo do segundo semestre de 2013. Até hoje os efeitos dessa onda estão longe de serem vistos, sentidos e interpretados em sua totalidade, seja pela academia, pelos partidos, pelos políticos no exercício de seus mandatos eletivos, seja pela sociedade que acompanhou as narrativas (des)qualificadoras que circularam pela grande mídia. Dependendo do ponto de vista do observador, ou seja, de estar nas ruas, nas redes digitais, lendo as revistas, os jornais, ou assistindo os noticiários na televisão, pode-se perceber a conformação de um campo discursivo sobre os acontecimentos com traços nítidos de uma guerrilha informacional, onde o que estava em jogo era a (des)construção do que era (i)lógico, (i)legítimo e/ou (i)legal.

O que ganhou o nome de Jornadas de Junho, grosso modo, consistiu em uma espécie de transbordamento da indignação coletiva, que saturada pelos discursos compartilhados nas mídias sociais transmutou-se em ação, ocupando as ruas das principais metrópoles brasileiras. Nas cidades, as vozes que bradavam por mudança na gestão urbana bem como no cenário econômico e político nos níveis local e nacional, os corpos, mascarados ou não, que se deslocavam, sobretudo, no centro de São Paulo e do Rio de Janeiro uniram-se em uma insatisfação civil que, para os especialistas, parecia ressoar de algum ponto da história recente que ainda buscam situar no espaço e no tempo: Paris, em maio de 1968? Chiapas, em 1994? Seattle, em 1999? Egito, em 2010?

Entre as vozes engrossadas nos protestos mencionados acima e a polifonia que se ouviu em junho de 2013, no Brasil, muitas outras manifestações aconteceram em diferentes partes do mundo, como em Davos (Suíça), por ocasião do Fórum Econômico Mundial, e em Toronto (Canadá), durante a reunião do G20. Essa multidão heterogênea que faz suas vozes ecoarem nos espaços urbanos não deve ser confundida com um corpo social, ou seja, como algo único, e, por isto, devidamente organizado. As singularidades que se encontraram no espaço público nesses diferentes países - e no Brasil - são a própria "carne" da sociedade (NEGRI, 2003), despida de qualquer tecido homogeneizante que, em seu movimento, procura criar novas formas de vida no mundo contemporâneo.

Diante desse contexto de insatisfação civil, em que circularam informações e afetos, articulando, em rede, as mobilizações que aconteceram no mundo real, este trabalho tem 
como objetivo contribuir para o entendimento das Jornadas de Junho, mas, em um exercício teórico de discussão situado na intersecção entre o campo da Ciência da Informação (CI) e a teoria social. Ciência essa entendida aqui como àquela que lida com o estudo dos processos informacionais em dimensões amplas, o que se dá em função de sua constituição interdisciplinar (BORKO, 1968; SHERA, 1983; SARACEVIC, 2009). Nessa direção são mobilizados quatro conceitos operacionais que se conectam ao projeto de pensar os protestos de junho de 2013 no Brasil. Dois deles são os conceitos de informação e de rede, que em suas transversalidades (MARTELETO, 2007) ajudam a olhar os fenômenos sociais produzidos e/ou relacionados aos dispositivos técnicos, recursos que potencializam a comunicação e viabilizam formas remotas e reticulares de ação coletiva, a exemplo do que aconteceu nas Jornadas de Junho.

$\mathrm{Na}$ análise proposta, recorre-se também a dois conceitos spinozanos, o de afeto e o de multidão, este último, aliás, atualizado por Hardt e Negri (2004) em sua releitura crítica da potência da ação coletiva no capitalismo contemporâneo. Trata-se, pois, de uma escolha autoral, uma perspectiva que se justifica pelo entendimento de que as possibilidades infocomunicativas oferecidas pela Internet tiveram papel preponderante nas manifestações que, em suas insatisfações, ocuparam as ruas e tornaram visível uma multiplicidade de singularidades em seu desejo irrefreado de liberdade e de democracia. Uma multidão que interagia principalmente pelas redes digitais, sem causar qualquer desconforto ao Estado e à grande mídia, até decidir ocupar as ruas.

\section{Informação: do conceito à circulação nas redes digitais}

Diferentemente de outras mobilizações históricas que ocuparam o espaço público, as manifestações recentes no Brasil e alhures estão relacionadas à produção, à circulação e ao acesso à informação via redes digitais. Uma realidade que a sociedade brasileira só começou a experimentar a partir de 1995, e que atualmente conta com cerca de 24,3 milhões de domicílios conectados à Internet, e com 139,8 milhões de usuários de serviços de telefonia móvel, segundo dados divulgados pelo Centro de Estudos sobre as Tecnologias da Informação e da Comunicação - CETIC (NÚCLEO DE INFORMAÇÃO E COORDENAÇÃO DO PONTO BR, 2014). Desses últimos, $24 \%$ se fazem presentes na Grande Rede Mundial de Computadores por meio de celulares, o que para Cocco (2009) se coloca como o recurso popular pelo qual os indivíduos são incorporados ao ciclo produtivo no 
Jornadas de Junho: uma leitura em quatro conceitos para a Ciência da Informação

capitalismo cognitivo. Sob o princípio da convergência digital, os celulares se transformaram em uma espécie de minicomputadores pelos quais os indivíduos podem acessar a Internet, e, deste modo, construírem novas experiências sociais, infocomunicativas e de subjetivação.

De um modo geral, os dados do CETIC permitem construir uma visão sobre a realidade brasileira quanto aos cidadãos que experienciam processos infocomunicativos mediados pelas tecnologias digitais. É bem verdade que na vida cotidiana os indivíduos estão mergulhados permanentemente no intercambiamento de informações nas relações sociais face a face, quer em situações formais ou informais. Todavia, nas redes digitais, o registro das ideias na forma de texto escrito, de sons e/ou de imagens adquire outra grandeza, uma vez que tudo aquilo que é fixado pode ser (re)visitado quantas vezes forem necessárias, permitindo não apenas a (re)produção de significados, mas também a ressignificação sobre o que se viu, ouviu e/ou sentiu anteriormente. É o étimo latino informatio fornecendo o sentido primeiro de que a informação é aquilo que molda a mente humana (CAPURRO; HJORLAND, 2007) e, desta maneira, produz o conhecimento em seu sentido lato.

Uma busca conceitual que permita entender a circulação da informação nas redes digitais pode fornecer pistas interessantes para estabelecer uma correlação entre o pensamento de Capurro e o de Belking e Robertson. Ao se ocupar da epistemologia da CI e inspirado por Thomas Khun, Capurro (2003) identifica um segundo paradigma que sustenta os estudos no campo, o que denomina como paradigma cognitivo. Para ele, tal como na Documentação, a CI concentrou parte de seus esforços investigativos no sentido de aperfeiçoar os mecanismos de recuperação dos conteúdos registrados em publicações impressas, sobretudo naquelas de interesse para a Ciência, o que remete aos conceitos de informação e de texto em Belking e Robertson (1976). Para esses autores, e em sentido amplo, o texto é um conjunto de signos propositalmente ordenado, com a intensão de provocar alterações nas estruturas mentais dos indivíduos, resultando, deste modo, em um novo conhecimento. Entende-se então que, quando assimilado em seu significado, o texto converte-se em informação, isto é, naquilo que tem potência para gerar outros conhecimentos nos indivíduos (BELKIN; ROBERTSON, 1976) alargando, assim, as possibilidades de ação no mundo.

Em uma dimensão semântica, a informação só faz sentido quando assimilada, algo que ocorre segundo um processo complexo e dinâmico, mediado pela interação comunicativa entres sujeitos, precisamente quando estes colocam suas competências linguísticas em ação. Desse modo, em linhas gerais, é possível falar em dois momentos distintos e complementares

InCID: R. Ci. Inf. e Doc., Ribeirão Preto, v. 6, n. 2, p. 5-19, set. 2015/fev. 2016. 
no ato comunicativo, isto é, no processo de intercambiamento da informação. No momento da transmissão, a interação entre os falantes pressupõe que estes conheçam e sejam capazes de manejar certas regras linguísticas, a fim de que possam conferir estrutura lógica ao discurso que desejam exteriorizar, que desejam tornar comum. No momento da recepção da informação, por sua vez, o discurso está condicionado às habilidades cognitivas dos sujeitos, por meio das quais eles podem, ou não, produzir sentido sobre o que é comunicado em um dado contexto.

Inscrita na mente, registrada em qualquer que seja o suporte ou circulando pelas redes digitais, ao falar em informação se está falando de um conceito que, paradoxalmente, pertence a todos e a ninguém, ainda que a CI a tenha reivindicado como objeto de estudo desde os anos de 1960. Sustentada pelo Dictionnaire Critique de la Communication, organizado por Lucien Sfez ${ }^{1}$, Marteleto (2007) destaca o caráter transversal do conceito de informação, que perpassa por diversas áreas do conhecimento, mas, sem fixar-se a nenhuma delas. Nessas passagens, a informação adquire contornos semânticos particularizados, tal como revelam Capurro e Hjorland (2007) acerca dos sentidos possíveis desse conceito nas Ciências Naturais, nas Ciências Humanas e Sociais e na própria CI, o que acaba por produzir uma dificuldade em sua precisão científica, e, por outro lado, estimular a capacidade imaginativa de quem a estuda.

É assim que a informação pode ser qualificada como um "conceito-viajante" (BAREL; CAUQUELIN, 1993 apud MARTELETO, 2007, [p. 4]), que simultaneamente provoca e sofre mudanças nos domínios epistemológicos por onde quer que passe. Se no campo científico sua variabilidade semântica é uma realidade reconhecida por diferentes autores na CI, e em outras áreas, o que dizer nos demais domínios da sociedade, onde é possível encontrar a heterogeneidade de indivíduos e/ou grupos que, por exemplo, ganharam as ruas nas Jornadas de Junho e para os quais a informação pode assumir uma multiplicidade de significados, sobretudo em um fundo político de ação coletiva. Agentes esses que experimentam, dia após dia, a copresença nas redes digitais, intercambiando informações carregadas de sentidos, de afetos, ou, no dizer de Castells (2013), de indignação e de esperança sobre as condições de vida nas metrópoles brasileiras, aspecto este discutido à luz de outro conceito-viajante, o de rede.

\footnotetext{
${ }^{1}$ Precisamente, a obra: BAREL, Y.; CAUQUELIN, A. Concepts transversaux. In: SFEZ, L. Dictionnaire critique de la communication. Paris: Presses Universitaires de France, 1993. v. 1. p. 179-290.
} 


\section{Tecendo uma rede conceitual para as Jornadas de Junho: rede, afetos e multidão}

Enquanto para o senso comum a noção de rede é mais facilmente percebida nos últimos anos a partir de mídias digitais como Orkut, Facebook e Twitter, a construção do conceito é histórica, remetendo a um tempo muito anterior ao aparecimento da Internet. Segundo Dortier (2010, p. 541), a palavra rede (network) tem origem no latim restis, com o sentido primeiro de "entrelaçamento de fios". No século XVIII, o termo foi empregado por médicos para fazer referência ao sistema circulatório, e, no século XIX, por engenheiros, que o aplicaram em projetos telegráficos e ferroviários (MERCKLÉ, 2003-2004; PARROCHIA, 2005), elementos estes que permitiram a intercomunicação no mundo moderno, contribuindo para a progressiva redução das distâncias entre países e continentes, e, consequentemente, entre pessoas.

Nas Ciências Sociais, o uso do termo é relativamente recente, o que Marteleto (2001) situa ao final da Segunda Guerra Mundial (1939-1945), tendo se ampliado sobretudo a partir do período posterior conhecido como Guerra Fria (1945-1991). Precipuamente foi no campo da Antropologia e da Sociologia que se desenvolveram os primeiros estudos interessados pela análise e pela compreensão das relações sociais com a utilização da noção de rede, tal como registra o trabalho de Barnes (1977), dentre outros. Ao estudar os membros de uma comunidade norueguesa conhecida como Bremmes, esse antropólogo emprega o conceito de rede como uma ferramenta de análise para entender a organização social de seus integrantes. Desse modo, para além do conceito de classe social, que organiza a sociedade segundo critérios socioeconômicos, Barnes olha os processos de interação entre indivíduos e grupos em escalas menores (os cliques), dentro de cada classe em que são formadas as redes sociais (social network), isto é, de acordo com critérios de parentesco, de amizade, de conhecimento e/ou de afinidade, tendo como função a obtenção potencial de benefícios.

Tal como informação, o conceito de rede também se caracteriza por sua transversalidade, deslocando-se por campos epistêmicos distintos até ganhar a forma e o sentido com o qual é empregado na contemporaneidade nas Ciências Sociais e, mais recentemente, na CI. Logo, quando se fala em redes sociais se está designando, grosso modo, as relações sociais que indivíduos, grupos ou organizações são capazes de manter direta ou indiretamente entre si. O componente tecnológico na mediação dessas relações, dado pelas inovações nas telecomunicações e na informática é apenas um ingrediente a mais nas interações entre os atores. Tal como observa Martino (2014), a transposição do conceito de 
redes sociais para Internet nada mais é do que uma iniciativa ainda recente de tentar analisar as relações humanas em ambiente virtual, culminando, deste modo, em termos do tipo redes sociais online, redes sociais conectadas, redes sociais digitais, ou simplesmente redes digitais, sendo este último o escolhido para nossa discussão. Com efeito, a infraestrutura que sustenta as redes digitais abre novas possibilidades de experimentar o contato com o outro, em um espaço simbólico, marcadamente digital, pelo qual trafegam informações de diferente natureza que - uma vez codificadas em linguagem binária - passam a sintetizar tipos diversos de conhecimento na forma de texto, de imagem e/ou de som.

Ao se pensar as Jornadas de Junho em sua estratégia de mobilização, chama a atenção o papel das redes digitais como o Facebook e o Twitter no sentido de catalisar e de fazer circular sentimentos, opiniões, reclamações e denúncias sobre as condições de vida no mundo real. Em seu conjunto, esses conteúdos se tornaram acessíveis por meio de computadores e de celulares que instrumentalizaram o desejo de protesto em face da indignação coletiva. Nessa direção, entende-se que conhecidos ou não, próximos ou distantes, partidários ou divergentes em suas crenças e ideologias, os indivíduos e os grupos heterogêneos que se relacionam nas redes digitais são movidos por seus afetos para pensar as injustiças, a precarização da vida, os privilégios das elites, bem como as omissões e a ineficiência dos serviços públicos, ou, ainda, os abusos de poder por parte do Estado e do mercado. Logo, foram os afetos amalgamados que contribuíram para o agir da multidão nas ruas do país, pois, como bem ensina Spinoza (2009a) na obra "Ética", os afetos também são forças que animam os indivíduos em direção à ação política. Ação essa que não se realiza sem um processo autônomo e contínuo de coleta, seleção, organização, compartilhamento e uso de informações.

Em Spinoza (2009a) é possível encontrar um pensamento ético-político que se expressa pela ideia de que os seres humanos não agem orientados somente pela via da razão, mas também por seus afetos, fonte de conhecimento e de subjetivação capazes de aumentar ou de diminuir a potência da ação. Correspondendo ao que se tem atualmente como sentimentos, mais basicamente aos estados do corpo em relação ao estado de outro(s) corpo(s), os afetos primitivos spinozanos são os seguintes:

a) Desejo: inato à condição humana, o desejo, apetite, vontade ou impulso é o afeto que determina o ser humano a agir de alguma maneira e em alguma direção; 
b) Alegria: é o estado de passagem de uma perfeição menor para uma maior; é o sentimento que impacta positivamente a ação humana, encorajando os indivíduos e/ou grupos a realizarem seus desejos; e

c) Tristeza: é o estado de passagem de uma perfeição maior para uma menor; é o sentimento que impacta negativamente a potência da ação humana, diminuindo nos indivíduos e/ou nos grupos, a vontade de realização dos desejos.

Além dos afetos primitivos citados acima, Spinoza ocupa-se de outros que se relacionam a eles, a saber: o medo (a insegurança resultante de uma situação passada ou futura, que leva o indivíduo à evitação de um mal que acredita estar por vir); a indignação (o sentimento que exprime o estado de ódio de uma pessoa por outra, em razão de ter feito mal a alguém); e a esperança (o sentimento de alegria instável diante de um desejo que a pessoa pode ou não realizar, daí sua relação com o afeto do medo, que está igualmente assentado na dúvida).

Basicamente são esses afetos spinozanos que ajudam a pensar as motivações para o agir recente dos indivíduos e dos grupos não só no Brasil, mas também no Egito, EUA, Espanha, Tunísia, Iêmen, Marrocos, Líbia e na Turquia, ou onde quer as mobilizações sinalizem os descontentamentos da população para com a economia e com a política nestes tempos de mundo globalizado. Em sua totalidade, esses protestos seguiram a mesma estratégia infocomunicativa, sustentando-se por uma articulação que transitava das redes digitais para as ruas, e vice-versa.

E se além de informações e de conhecimentos esses protestos mobilizaram afetos, cabe destacar que uma perspectiva similar a de Spinoza aparece na obra do sociólogo espanhol Manuel Castells. Inspirado nos estudos neurocientíficos sobre emoção e cognição humanas de Antonio Damasio e de Hanna Damasio, Castells (2013) reconhece o papel do medo, da indignação e da esperança nas motivações individuais para as manifestações recentes na história que contabiliza desde janeiro de 2011, quando uma multidão de egípcios contrários ao regime de Hosni Mubarak ocupou as ruas do Cairo, resultando em uma série de confrontos violentos com a polícia.

Castells não tem dúvidas de que a Primavera Árabe, o Occupy Wall Street, os Indignados na Espanha e as Jornadas de Junho são movimentos emocionais, o que o aproxima do pensamento de Spinoza sobre o papel dos afetos na potência da ação política dos 
indivíduos e dos grupos. Nessa direção, Castells (2013) explica, em linhas gerais, que um movimento social tem início no instante em que as emoções são transformadas em ação. Assim, quando indivíduos se sentem afetados pela ação injusta de um determinado agente tem-se a possibilidade do encontro entre os que compartilham desse sentimento de indignação, o que os motiva a reagir. Superado o medo de fazer algo contra as injustiças, sobretudo no enfrentamento ao aparelho coercitivo do Estado em seu monopólio da violência, as pessoas são tomadas por um entusiasmo que as impele a confrontar riscos em prol de uma esperança que valida o desejo comum de mudança, resultando, assim, nas lutas sociais.

Analisando a crescente interação humana nas redes digitais, Castells (2010; 2013) aponta a comunicação e, consequentemente, os processos de intercambiamento de informações e de conhecimentos - como o fio que permite conectar diferentes indivíduos e grupos em torno da mobilização para a ação coletiva nas ruas. Logo, ao colocarem em circulação ideias, opiniões e sentimentos, e ao compartilharem indignação diante de condições tão desiguais de vida, as pessoas encontram correspondência, apoio e encorajamento em outros indignados. E como bem observa Castells (2013, p. 19) sobre a interação desses indignados na Internet, a "empatia no processo de comunicação é determinada por experiências semelhantes as que motivaram o acesso emocional inicial”. Por isso as redes digitais têm se mostrado canais de comunicação eficientes, notadamente pela rapidez com que levam a cabo esse encontro de singularidades que, em comum, partilham do sentimento de humilhação, de exploração e de desassistência diante de uma representação política que se encontra em crise ao se afastar da defesa dos interesses comuns, firmando cada vez mais seu compromisso com os interesses privados, com a manutenção das relações de dominação e com as formas de concentração do poder.

O encontro ao acaso dos indignados nas redes digitais lembra, ainda, o discurso de Althusser (2005) sobre o clinamen (declinação) de Epicuro. Em uma leitura contemporânea do atomismo epicuriano sobre os desvios que ocorrem durante a queda retilínea dos átomos, produzindo choques a partir dos quais os corpos são gerados, Althusser vê o encontro entre indivíduos para o agir político como algo que se dá de maneira similar e imprevisível na história. Todavia, mesmo que as circunstâncias políticas, econômicas e/ou sociais levem as pessoas a se encontrarem de forma mais ou menos duradoura na luta estas não chegam a constituir uma unidade propriamente dita, um pensamento que remete a discussão ao conceito spinozano de multidão.

InCID: R. Ci. Inf. e Doc., Ribeirão Preto, v. 6, n. 2, p. 5-19, set. 2015/fev. 2016. 
Em seu pensamento sobre o direito natural para além de uma visão individualista, sendo por isto orientado pelo princípio do comum, Spinoza (2009b) o vislumbra a partir da potência (potentia) da multidão (multitudo), isto é, de uma multiplicidade de indivíduos que constitui o Estado, prisma que considera ser o único meio para se pensar a política na cidade. Trata-se, pois, de um conceito que se opõe ao modo como o mesmo é utilizado por Hobbes (2009). Para o autor de Leviatã, a multidão se converte em um corpo uniforme de cidadãos (o povo) que, por meio de um pacto, concede o poder a uma só pessoa (o soberano), passando esta a representar os indivíduos enquanto unidade (HOBBES, 2009), assumindo, em função dessa cessão, uma condição política passiva. Ademais, em Hobbes (2009), a multidão figura de maneira negativa, sendo retratada como um corpo desorganizado, irracional, como turba que precisa ser controlada para que a nação possa ser governada em clima de ordem e de paz. Sentido exato pela qual as Jornadas de Junho foram tratadas pelo Estado e pelos meios de comunicação dominantes.

O sentido positivo da multidão é retomado contemporaneamente por Hardt e Negri (2004). Dotada de autonomia e de uma força transformadora, no entendimento desses autores a multidão tem como projeto a construção de uma democracia absoluta, ou seja, livre, igualitária, aberta e inclusiva. Expressa por uma multiplicidade de pessoas em suas individualidades, que não pode ser reduzida a categorias homogeneizantes de idade, etnia, orientação política, religiosa, sexual e de classe social, Hardt e Negri (2004) falam de encontros que ocorrem em novos circuitos de cooperação e de colaboração que ultrapassam as fronteiras nacionais. Logo, assumem o papel das redes sociais e digitais na medida em que propiciam o compartilhamento de informações, de conhecimentos e de afetos capazes de potencializar suas ações. Uma leitura que ajuda a pensar as manifestações no Brasil e que tiveram repercussão na imprensa internacional.

Como acontecimento imprevisível, o encontro das singularidades nas redes digitais e nas ruas do Brasil teve início com o Movimento Passe Livre - MPL contra o aumento de R\$ 0,20 na tarifa de ônibus, em São Paulo e no Rio de Janeiro, mas acabou por ressoar em outras 120 cidades, revelando-se bem mais que isto, especialmente ao permitir o afloramento de uma diversidade de reivindicações na esfera da educação, da habitação, da saúde e da segurança pública (SECCO, 2013; MOVIMENTO, 2013). Reivindicações antigas e novas, todas ofuscadas nos últimos anos pela priorização dos investimentos públicos nas obras destinadas aos megaeventos, a exemplo da Copa do Mundo, realizada em 2014, e dos Jogos Olímpicos, agendados para 2016.

InCID: R. Ci. Inf. e Doc., Ribeirão Preto, v. 6, n. 2, p. 5-19, set. 2015/fev. 2016. 
O mosaico de frases que circularam pelas redes digitais e depois transbordaram para as ruas do país são sínteses das ideias e dos temas que inquietavam os brasileiros durante todo o período em que as Jornadas de Junho se materializaram. "Somos a rede social”, "Olha que legal, o país parou nem é carnaval”, "Sem educação, sem saúde, sem paciência”, "Queremos escolas e hospitais "padrão FIFA", "Vote em ideias, não em pessoas", “Abaixo o fanatismo e a corrupção religiosa", "Mais amor, por favor", "Meu cu é laico", "Não queremos Copa do Mundo", "Saímos do Facebook", "Não somos conduzidos. Conduzimos!", "Marco civil da Internet já!", entre outras externalizações, forneceram o mote para uma pluralidade de insatisfações e desejos, aproximando indivíduos que necessariamente não se conheciam no mundo real, porém, constituíam uma multidão encorajada a ocupar as ruas das cidades ao mostrar que não estavam sós em sua indignação, fosse com a realidade local ou nacional.

Em sua força criadora essa multidão colocou em cheque as estratégias tradicionais de protestos que dão segurança à interlocução com o governo e com a grande mídia, surpreendo a tudo e a todos. Sem megafones, sem carros de som, sem palanques e sem a figura clássica do líder carismático (SECCO, 2013), a organização múltipla, fluida e autônoma da multidão seguiu uma lógica rizomática que dificultou o trabalho dos meios de comunicação dominantes e, principalmente, da polícia. Desse modo, sem conseguir identificar lideranças com as quais pudessem dialogar para por fim aos protestos, os poderes Executivo e Legislativo responderam com uma nova legislação para restituir a ordem. Uma reação que se deu precisamente pela criação da Lei Federal n $n^{\circ} 12.850$ (Lei de Organização Criminosa), promulgada pela presidente Dilma Rousseff, em dois de agosto de 2013, e pela Lei Estadual $\mathrm{n}^{\circ} 6.528$ (Lei Contra as Máscaras), promulgada pelo então governador do Rio de Janeiro, Sergio Cabral, em 11 de setembro de 2013.

A criação de instrumentos legais para controlar as manifestações populares no Brasil fornece a dimensão nítida da força imprevisível e incontrolável da multidão que saiu às ruas em junho de 2013. E pelo que foi possível observar, não se tratava de uma incoerência de corpos e de vozes orientada pela violência, tal como a grande mídia insinuava diariamente sobre esse acontecimento. Em sua multiplicidade, as reivindicações que se articulavam entre as redes digitais e as ruas sinalizavam o desejo comum de mudança. Mudança na cultura política brasileira, eivada por práticas eleitoreiras e pela corrupção generalizada; na forma como a religião tem interferido no Estado, obstruindo o avanço da cidadania para grupos que permanecem alijados de direitos civis; na precariedade com que os serviços públicos de saúde, de educação e de segurança são oferecidos à população; bem como os 
descontentamentos com a infraestrutura urbana, com os serviços de transporte e com as tarifas que dificultam a mobilidade nos espaços metropolitanos.

Além disso, havia indivíduos e grupos que lutavam por direitos concernentes à informação, reclamando, naquele momento, a aprovação do Marco Civil da Internet, hoje Lei Federal n. 12.965, sancionada em 23 de abril de 2014. Em seu conjunto, as mobilizações que deram forma às Jornadas de Junho mostram que as redes digitais se tornaram mais do que recursos tecnológicos de trabalho, de estudo e de entretenimento. Atualmente elas representam um complexo e capilarizado laboratório de cidadania. Um ambiente virtual e descentralizado de experimentação política autônoma, cuja arquitetura distribuída parece estar longe de ser completamente dominada pelos partidos políticos, com suas escolas e fórmulas obsoletas de formação da militância, bem como pelos meios de comunicação dominantes. Esses últimos, aliás, cada vez mais contrabalançados pelo lento e progressivo empoderamento civil no uso dos recursos tecnológicos para a exploração de alternativas outras de acesso à informação e ao conhecimento.

\section{Palavras finais}

Longe de dar conta da totalidade dos acontecimentos ligados às Jornadas de Junho, o trabalho se ocupou, em linhas gerais, de entender as manifestações pelos conceitos de informação, rede, afetos e multidão. Um acontecimento histórico no qual o agir dos indivíduos ganhou as ruas por meio de uma intensa articulação social mediada por dispositivos tecnológicos de comunicação e de informação. Não se quer dizer com isso que sem as redes digitais a onda de manifestações que se proliferaram pelo Brasil não teria sido possível, pois, tal como registra a história, em diferentes momentos e contextos políticos e sociais segmentos indignados da sociedade se encontraram para lutar contra as injustiças e os abusos do Estado e do mercado, mesmo quando a violência se impôs em toda sua força contra a vida humana.

Pelo que se pode analisar a partir das Jornadas de Junho, o que as redes digitais fazem é potencializar a luta, na medida em que tornam mais rápida a circulação de informações, de conhecimentos e também de afetos, permitindo, desse modo, a aproximação de indivíduos e/ou de grupos que têm seu espaço de ação coletiva ampliado para além das ruas. Foi nesse sentido que ganhou notoriedade a força da multidão no Rio de Janeiro, em resposta à 
repressão ostensiva da Polícia Militar - PM à manifestação do dia 13 de junho, na capital paulista. As informações e os afetos que circularam pela grande mídia e pela mídia alternativa só aumentaram o sentimento de indignação. E o que deveria ter intimidado a multidão pelo medo acabou por encorajá-la, desencadeando outros protestos pelo país.

Se as Jornadas de Junho e suas conexões com outros protestos internacionais revelam os usos sociais das redes digitais para o ciberativismo, no Brasil, por outro lado, elas explicitam toda sua eficiência técnica como dispositivo de vigilância e de controle. Como se pode dizer com base em Foucault (2010), elas também se transformam em instrumentos de biopoder, isto é, em meios que se colocam a serviço de um poder que se dirige sobre a vida da população, regulamentando-a, gerindo-a de muitas formas, inclusive agora, em seu direito de protestar. É essa ambivalência que configura as redes digitais como um espaço de lutas no qual as armas são dadas pelo volume de informações e de conhecimentos que os diferentes agentes são capazes de monitorar, capturar, mobilizar, fazer circular e/ou restringir, segundo estratégias de vigilância e de contra contravigilância que se atualizam dia após dia.

Enfim, as manifestações de que se falou até aqui são a expressão de uma realidade que oferece novas abordagens ao fenômeno da informação na sociedade contemporânea, colocando-se para além do discurso utópico do acesso livre e universal, muito em voga na literatura especializada em CI, especialmente entre os anos de 1980 e 1990, e que ainda segue muito forte neste século. Movimentos sociais como o que emergiu em junho de 2013 no Brasil abrem caminhos para se pensar a informação como dotada de uma força viva, na medida em que mescla a razão e os sentimentos dos indivíduos. Por conseguinte, como algo que se dinamiza no espaço dos fluxos, quer dizer, nas redes sociais e digitais pelas quais é mobilizada por uma multiplicidade de pessoas engajadas nas lutas por liberdades, por direitos, por justiça e pela própria vida, esse instante no qual é mais demandada, precisando por isto ser produzida, compartilhada, analisada e consumida pelos atores sociais em um tempo que é sempre urgente, tal como sempre é o desejo social de mudança. 


\section{Referências}

ALTHUSSER, L. A corrente subterrânea do materialismo do encontro (1982). Crítica marxista, São Paulo, n. 9, p. 9-48. 2005.

BARNES, J. A. Class and commitees in a Norwegian island parish. In: SAMUEL, L. (Ed.). Social networks: a developing paradigm. New York: Academic Press, 1977. p. 233-252. Disponível em: 〈http://pierremerckle.fr/wp-content/uploads/2012/03/Barnes.pdf>. Acesso em: 28 dez. 2013.

BELKING, N. J.; ROBERTSON, S. E. Information science and the phenomenon of information. Journal of the American Society for Information Science, v. 27, n. 4, p. 197204, jul./aug. 1976.

BORKO, H. Information science: what it is? American Documentation, v. 19, n. 1, p. 3-5, jan. 1968.

CAPURRO, R. Epistemologia e ciência da informação. In: ENCONTRO NACIONAL DE PESQUISA EM CIÊNCIA DA INFORMAÇÃO, 5., 2003, Belo Horizonte. Anais... Belo Horizonte: ANCIB, 2003. Disponível em: <http://www.capurro.de/enancib_p.htm>. Acesso em: 11 dez. 2013.

.; HJORLAND, B. O conceito de informação. Perspectivas em Ciência da Informação, Belo Horizonte, v. 12, n. 1, p. 148-207, jan./abr. 2007. Disponível em: $<$ http://www.scielo.br/scielo.php?script=sci_pdf\&pid=S141399362007000100012\&lng=en\&nrm=iso\&tlng=pt>. Acesso em: 16 mar. 2013.

CASTELlS, M. A sociedade em rede. 13. reimp. São Paulo: Paz e Terra, 2010.

Redes de indignação e esperança: movimentos sociais na era da internet. Rio de Janeiro: Zahar, 2013.

COCCO, G. O que o mundo se tornou. In: . MundoBraz: o devir-mundo do Brasil e o devir-Brasil no mundo. Rio de Janeiro: Record, 2009. p. 111-166.

DORTIER, J. F. Rede. In: Dicionário de ciências humanas. São Paulo: Martins Fontes, 2010. p. 541, 542.

FOUCAULT, M. Aula do dia 17 de março de 1976. In: Em defesa da sociedade. 2. ed. São Paulo: Martins Fontes, 2010. p. 201-222.

HARDT, M.; NEGRI, A. Multitude: war and democracy in the Age of Empire. New York: Peguin, 2004.

HOBBES, T. Leviatã: ou matéria, forma e poder de um Estado eclesiástico e civil. São Paulo: Martin Claret, 2009. 
MARTELETO, R. M. Análise de redes sociais: aplicação nos estudos de transferência da informação. Ciência da Informação, Brasília, v. 30, n. 1, p. 71-81, jan./abr., 2001.

Disponível em: <http://www.scielo.br/pdf/ci/v30n1/a09v30n1.pdf>. Acesso em: 02 dez. 2013. Informação, redes e redes sociais: fundamentos e transversalidades. Informação \&

Informação, Londrina, v. 1 2, n. esp., não paginado, 2007. Disponível em:

<http://www.uel.br/revistas/uel/index.php/informacao/article/view/178>. Acesso em: $12 \mathrm{dez}$. 2013.

MARTINO, L. M. S. Redes sociais. In: Teoria das mídias sociais: linguagens, ambientes e redes. Petrópolis: Vozes, 2014. p. 55-81.

MERCKLÉ, P. Les réseaux sociaux: les origines de l'analyse des réseaux sociaux. 20032004. Disponível em: 〈http://eco.ens-lyon.fr/sociales/reseaux_merckle_03_origines.pdf>. Acesso em: 16 dez. 2013.

MOVIMENTO PASSE LIVRE SÃO PAULO. Passe livre: não começou em Salvador, não vai terminar em São Paulo. In: CIDADES rebeldes: passe livre e as manifestações que tomaram as ruas do Brasil. São Paulo: Boitempo, 2013. p.13-18.

NEGRI, A. Cinco lições sobre Império. Rio de Janeiro: DP\&A, 2003.

NÚCLEO DE INFORMAÇÃO E COORDENAÇÃO DO PONTO BR. Centro de Estudos sobre as Tecnologias da Informação e da Comunicação. TIC, domicílios e empresas 2013: pesquisa sobre o uso de Tecnologia de Informação e Comunicação no Brasil. São Paulo, 2014. Disponível em:

<http://www.cetic.br/media/docs/publicacoes/2/TIC_DOM_EMP_2013_livro_eletronico.pdf> . Acesso em: 16 dez. 2013.

PARROCHIA, D. Quelque aspects historiques de la notion de réseau. Flux, n. 62, p. 10-20, Oct./Déc. 2005.

SARACEVIC, T. Information science. In: BATES, M. J.; MAACK, M. N. (Ed.).

Encyclopedia of Library and Information Science. New York: Taylor and Francis, 2009, p. 2570-2586. Disponível em:

$\langle$ http://comminfo.rutgers.edu/ tefko/SaracevicInformationScienceELIS2009.pdf $>$. Acesso em: 26 nov. 2013.

SECCO, L. As jornadas de junho. In: CIDADES rebeldes: passe livre e as manifestações que tomaram as ruas do Brasil. São Paulo: Boitempo, 2013. p. 71-78.

SHERA, J. H. Librarianship and information science. In: MACHLUP, F.; MANSFIELD, U. (Ed.). The study of information: interdisciplinary messages. New York: John Wyley \& Sons, 1983. p. 379-388.

SPINOZA, B. Ética. Belo Horizonte: Autêntica, 2009a.

Tratado político. São Paulo: Martins Fontes, 2009b. 